\title{
PERBAIKAN SISTEM TRANSPORTASI DENGAN SIMULASI PROMODEL UNTUK MENINGKATKAN RITASI PENGIRIMAN BARANG DI PT. XXX
}

\author{
Ismail Kurnia $^{1}$, Dwikha Wiriyawan Pamungkas ${ }^{2}$, Prima Fithri ${ }^{3}$ \\ ${ }^{1,2}$ Program Studi Teknik Industri, Fakultas Teknik, Universitas Krisnadwipayana \\ ${ }^{3}$ Teknik Industri, Fakultas Teknik, Universitas Andalas \\ Email: ismailkurnia@yahoo.com,
}

\begin{abstract}
Abstrak: Di dalam proses pengiriman barang efisiensi transportasi sangatlah penting, dimana dalam penelitian ini terdapat permasalahan terkait muatan beban yang tidak maksimal dan menyebabkan lebihnya penggunaan armada pengirim barang serta profit perusahaan pengguna jasa pengiriman apabila pengiriman berjalan secara terus - menerus dalam periode waktu tertentu, dalam penelitian ini dibahas bagaimana maksimalisasi beban muat digunakan. Selanjutnya permasalahan efisiensi dalam waktu proses pengiriman barang juga berdampak kepada banyaknya jumlah penggunaan armada untuk mengirim barang / produk. Pada masa kini dengan perkembangan dunia komputer maka digunakan program Promodel untuk membangun simulasi model untuk menganalisa sistem kerja pengiriman barang serta melakukan perbaikan sistem.
\end{abstract}

Kata kunci: Efisiensi, Transportasi, dan Promodel

Abstract: In the process of shipping goods transportation efficiency is very important, where in this study there are problems related to loads that are not optimal and cause more use of the freight forwarder and the profit of the shipping service user if the shipment continuously for a certain period of time, in this study discussed how the load maximization is used. Furthermore, efficiency issues in the process of shipping goods also have an impact on the large number of fleets used to deliver goods / products. At the present time with the development of the computer world, the Promodel program is used to build simulation models to analyze the work system of shipping goods and make system improvements.

Keywords: Efficiency, Transportation, and Promodel

\section{PENDAHULUAN}

PT. Nanda Persada Transport sebagai perusahaan penyedia jasa distribusi barang baik produk dan bahan baku selama kurang lebih 19 tahun sejak tahun 1999 bagi Customer pengguna jasa, namun dalam praktek pelayanan dari perusahaan ini masih terdapat kendala pada bagian teknis maupun sitstem operasional kegiatan distribusi mengingat banyak faktor - faktor pendukung serta unsur unsur dalam sistem pengiriman terkait waktu muat barang, waktu perjalanan, hingga waktu penerimaan produk dan bahan baku yang dikirim serta kapasitas armada belum digunakan dengan optimal. Dengan adanya perkembangan teknologi pada masa kini terutama perkembangan teknologi informasi dan komputer diharapkan kemajuan teknologi ini dapat digunakan untuk membantu memecahkan permasalahan dalam kegiatan bisnis dan produksi dengan program yang mendukung untuk mengolah, menganalisa serta membuat simulasi, dalam kasus permasalahan sistem pengiriman dapat digunakan aplikasi Promodel untuk menggambarkan simulasi model dari sistem pengiriman berdasarkan sistem 
nyata yang berjalan dari kegiatan operasi pengiriman barang yang sesungguhnya.

\section{METODE PENELITIAN}

Penelitian ini diawali dengan pengumpulan data beradasarkan history pengiriman, lalu dilanjutkan dengan optimalisasi beban muat untuk mendapatkan jumlah ritasi yang seharusnya, dan dilanjutkan dengan pembangunan simulasi model dengan program Promodel.

\section{Pengumpulan Data}

Berikut ini adalah data diambil dari sistem GPS (Global Positioning System) pengiriman produk kimia dari PT. BASF Care Chemical, Cimanggis, Depok menuju PT. Reckitt Benckiser Indonesia, Narogong, Bogor pada bulan Januari sampai dengan bulan Maret 2019. Adapun rekapitulasi data adalah sebagai berikut:

Tabel 1. Rekapitulasi Data Januari s/d Maret 2019

\begin{tabular}{|c|c|c|c|c|c|c|}
\hline $\begin{array}{c}201 \\
9\end{array}$ & $\begin{array}{c}\text { Ju } \\
\text { mla } \\
\text { h } \\
\text { Har } \\
\text { i }\end{array}$ & $\begin{array}{c}\text { Ju } \\
\text { mla } \\
\text { h } \\
\text { Rit }\end{array}$ & $\begin{array}{c}\text { Tot } \\
\text { al } \\
\text { Vol } \\
\text { um } \\
\text { e } \\
(\mathbf{K g} \\
) \\
\end{array}$ & $\begin{array}{c}\text { Rata } \\
\text { - rata } \\
\text { waktu } \\
\text { muat/ } \\
\text { bulan } \\
\text { (jam) }\end{array}$ & $\begin{array}{c}\text { Rata - } \\
\text { rata } \\
\text { waktu } \\
\text { bongka } \\
\text { r/bulan } \\
\text { (jam) }\end{array}$ & $\begin{array}{c}\text { Rata - } \\
\text { rata } \\
\text { waktu } \\
\text { perjalan } \\
\text { an/bulan } \\
\text { (jam) }\end{array}$ \\
\hline $\begin{array}{l}\text { Janu } \\
\text { ari }\end{array}$ & 10 & 80 & $\begin{array}{l}356 \\
800\end{array}$ & 3:03 & $2: 37$ & $1: 23$ \\
\hline $\begin{array}{l}\text { Febr } \\
\text { uari }\end{array}$ & 9 & 72 & $\begin{array}{l}323 \\
200\end{array}$ & 3:03 & $2: 39$ & $1: 22$ \\
\hline $\begin{array}{l}\text { Mar } \\
\text { et }\end{array}$ & 7 & 56 & $\begin{array}{l}249 \\
600\end{array}$ & 3:05 & $2: 37$ & $1: 20$ \\
\hline $\begin{array}{l}\text { Tot } \\
\text { al }\end{array}$ & 26 & 208 & $\begin{array}{l}929 \\
600\end{array}$ & $9: 11$ & $7: 53$ & $4: 05$ \\
\hline $\begin{array}{l}\text { Rata } \\
\text { bulan) }\end{array}$ & - rata & (da & n 3 & 3:03 & $2: 37$ & $1: 21$ \\
\hline
\end{tabular}

Diketahui pula:

- Jarak Tempuh (BCCI - Reckitt) : $21 \mathrm{Km}$

- Jumlah armada digunakan/hari : 8 unit (truk fuso)

- Kecepatan rata - rata perjalanan :

Jarak perjalanan

Rata-rata waktu perjalanan

$\frac{21 \mathrm{~km}}{1 \mathrm{jam} 21 \mathrm{menit}}=\frac{21 \mathrm{~km}}{1,3 \mathrm{jam}}=16 \mathrm{~km} / \mathrm{jam}$
Dan diperoleh data beban muat sebagai berikut:

Tabel 2. Beban Muat Truk Berdasarkan Jumlah Drum

\begin{tabular}{ccc}
\hline $\begin{array}{c}\text { Jumlah } \\
\text { Muatan } \\
\text { (Drum) }\end{array}$ & $\begin{array}{c}\text { Kapasitas } \\
\text { Drum }(\mathrm{Kg})\end{array}$ & $\begin{array}{c}\text { Berat Total } \\
(\mathrm{Kg})\end{array}$ \\
\hline 22 & 200 & 4400 \\
24 & 200 & 4800 \\
27 & 200 & 5400 \\
\hline
\end{tabular}

Selanjutnya dapat kita hitung berapa jumlah rit pengiriman yang seharusnya tidak terjadi dalam pengamatan data pengiriman selama bulan Januari s/d Maret 2019:

Jumlah Rit menggunakan beban muat optimal:

Total Volume / Beban Muat 27 Drum $=\quad 929600 \mathrm{Kg} / 5400 \mathrm{Kg}$

$=\quad 172$ Rit

Jumlah Rit yang seharusnya tidak terjadi:

Total Rit Aktual 3 bulan - Total Rit menggunakan beban optimal

$\begin{array}{cc}= & 208 \text { Rit }-172 \text { Rit } \\ = & 36 \text { Rit }\end{array}$

\section{Membangun Simulasi Promodel}

Langkah terakhir dalam pengolahan data adalah membangun simulasi model menggunakan program Promodel. Dimana penyusunan simulasi model ini disusun menggunakan variabel data yang sudah didapatkan pada pengumpulan data sebelumnya yang dimana sudah dikonversikan: 


\section{Tabel 3. Variabel Data Beserta Konversi Simulasi}

\begin{tabular}{|l|l|l|}
\multicolumn{1}{|c|}{ Variabel } & \multicolumn{1}{c|}{ Nilai Actual } & \multicolumn{1}{c|}{ Konversi Simulasi } \\
\hline $\begin{array}{l}\text { Jarak Tempuh } \\
\text { Kecepatan Rata }\end{array}$ & $21 \mathrm{Km}$ & $21.000 \mathrm{~m}$ \\
\hline $\begin{array}{r}\text { rata } \\
\text { Waktu Loading } \\
\text { (muat) }\end{array}$ & $\begin{array}{l}3 \mathrm{Km} / \mathrm{h} \text { (Standar deviasi } \\
=0,0075)\end{array}$ & $266,667 \mathrm{mpm}$ \\
\hline $\begin{array}{l}\text { Waktu Unloading } \\
\text { (bongkar) }\end{array}$ & $\begin{array}{l}2,5 \mathrm{Jam} \text { (Standar deviasi } \\
=0,0031)\end{array}$ & $2,5 \mathrm{Jam}$ (Standar deviasi $=0,3$ ) \\
\hline $\begin{array}{l}\text { Waktu perjalanan } \\
1 \mathrm{Jam} 20 \text { Menit }\end{array}$ & 1 Jam 20 Menit \\
\hline $\begin{array}{l}\text { Jumlah Resource } \\
\text { (Truk Fuso) }\end{array}$ & 8 unit & 8 unit \\
\hline $\begin{array}{l}\text { Jumlah Entitas } \\
\text { Dikirim/hari } \\
\text { (@Rit }=5.400 \\
\mathrm{~kg})\end{array}$ & $43.200 \mathrm{Kg}$ & 8 entitas \\
\hline
\end{tabular}

Berikut adalah hasil pembangunan simulasi model pengiriman drum kimia dari PT. BASF Care Chemicals Indonesia, Depok menuju PT. Reckit Benckiser Indonesia, Bogor, dimana sudah digambarkan menggunakan layout, location, Resource, Path Network beserta dengan path network:

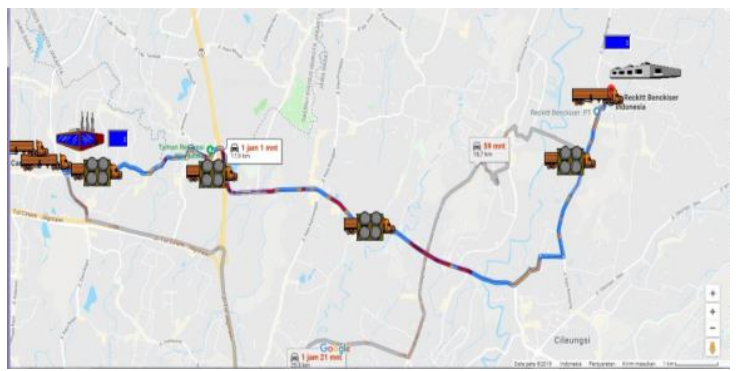

\section{Gambar 1. Simulasi Model Dijalankan} (Running)

Penyusunan simulasi model disusun menggunakan data yang sudah didapatkan pada pengumpulan data sebelumnya, adapun spesifikasi model yang dibangun dalam Promodel:

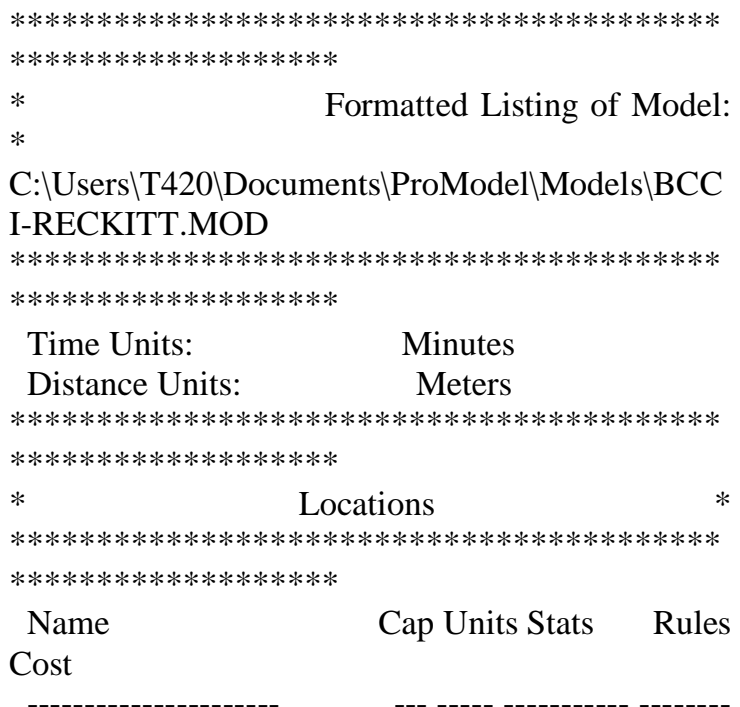

PT_BASF_Care_Chemicals INF 1 Time Series Oldest, ,

PT_Reckitt_Benckiser INF 1 Time Series Oldest, ,

*********************************************** $* * * * * * * * * * * * * * * * * * *$

************************************************

$* * * * * * * * * * * * * * * * * * *$

Name Speed (mpm) Stats Cost

Drum_Kimia $50 \quad$ Time Series

*********************************************** $* * * * * * * * * * * * * * * * * * * * \quad *$

Path Networks

$* * * * * * * * * * * * * * * * * * * * * * * * * * * * * * * * * * * * * * * * * *$ $* * * * * * * * * * * * * * * * * * *$

Name Type T/S From To BI Dist/Time SpeedFactor

\begin{tabular}{|c|c|c|c|c|}
\hline $\begin{array}{r}\text { Net1 } \\
21000\end{array}$ & $\begin{array}{c}\text { Passing } \\
1\end{array}$ & Speed & N1 & $\mathrm{N} 2$ \\
\hline
\end{tabular}

************************************************ $* * * * * * * * * * * * * * * * * * *$

* Interfaces *

$* * * * * * * * * * * * * * * * * * * * * * * * * * * * * * * * * * * * * * * * * *$

$* * * * * * * * * * * * * * * * * * *$

Net Node Location

Net1 N1 PT_BASF_Care_Chemicals N2 PT_Reckitt_Benckiser

********************************************** $* * * * * * * * * * * * * * * * * * *$

* Resources

$* * * * * * * * * * * * * * * * * * * * * * * * *$

$* * * * * * * * * * * * * * * * * * *$

Res Ent

Name Units Stats Search Search Path Motion Cost

Truk_Fuso 8 By Unit Closest Oldest Net1 Empty: $266.667 \mathrm{mpm}$

Home: N1

Full: $\quad 266.667 \mathrm{mpm}$

$* * * * * * * * * * * * * * * * * * * * * * * * * * * * * * * * * * * * * * * * *$ $* * * * * * * * * * * * * * * * * * *$

* Processing $* * * * * * * * * * * * * * * * * * *$

Process

Routing

Entity Location Operation Blk Output Destination Rule Move Logic

Drum_Kimia PT_BASF_Care_Chemicals wait $\mathrm{n}$ $(3 \cdot 0,0.7) \mathrm{hr}$ 


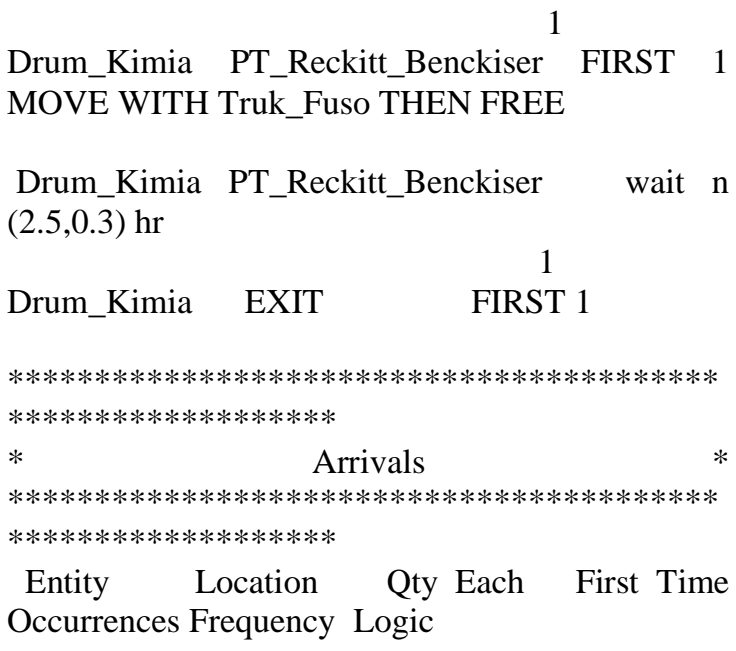

Drum_Kimia PT_BASF_Care_Chemicals 8 inf $8 \mathrm{hr}$

\section{HASIL DAN PEMBAHASAN}

Setelah kita melakukan simulasi dengan Promodel, maka akan mendapatkan hasil sebagai berikut :

\section{Meningkatkan Ritasi Pengiriman Dalam Simulasi Model}

Langkah yang diambil dalam memperbaiki sistem untuk meningkatkan ritasi pengiriman serta tingkat penggunaan sumberdaya (resource) truk fuso yaitu dengan memperbaiki waktu prosesnya. Dimana terdapat 3 (tiga) titik utama dalam sistem yaitu :

Tabel 4. Waktu Proses Operasi Pengiriman

\begin{tabular}{ccc}
\hline No & Proses & Waktu \\
\hline 1 & Loading & 3 Jam \\
2 & Delivering & 1 Jam 20 \\
& Menit \\
3 & Unloading & $2,5 \mathrm{Jam}$ \\
\hline
\end{tabular}

Dari tabel diatas diketahui bahwa:

a. Waktu proses muat (Loading) selama 3 jam yang dimana dapat diperbaiki.

b. Waktu proses pengiriman (Delivery) tidak diubah karena berkenaan dengan situasi dan kondisi trip perjalanan yang berubah - ubah, namun sudah diketahui rata - rata waktu perjalanan dari tiap armada. c. Waktu proses bongkar (Unloading) tidak diubah, dikarenakan prosedur di tempat tujuan yang sudah ditetapkan.

Selanjutnya kita akan melakukan perbaikan simulasi dengan mengurangi waktu proses muat (Loading). Adapun perbaikan yang dilakukan terdapat pada bagian Processing dalam simulasi model:

Tabel 5. Proses Operasi Pengiriman Dalam Simulasi Model

\begin{tabular}{ccc}
\hline No & $\begin{array}{c}\text { Diagram } \\
\text { Alir }\end{array}$ & Processing Promodel \\
\hline 1 & Loading & wait $\mathrm{n}(3.0,0.7) \mathrm{hr}$ \\
2 & Delivering & $\begin{array}{c}\text { MOVE WITH Truk_Fuso } \\
\text { THEN FREE }\end{array}$ \\
3 & Unloading & wait $\mathrm{n}(2.5,0.3) \mathrm{hr}$ \\
\hline
\end{tabular}

Maka kita ubah waktu muat (Loading) pada Processing simulasi model menjadi seperti tabel berikut:

Tabel 6. Perbaikan Proses Operasi Pengiriman Dalam Simulasi Model

\begin{tabular}{ccl}
\hline No & $\begin{array}{c}\text { Diagram } \\
\text { Alir }\end{array}$ & \multicolumn{1}{c}{ Processing Promodel } \\
\hline 1 & Loading & wait n $(2.0,0.7) \mathrm{hr}$ \\
2 & Delivering & MOVE WITH Truk_Fuso \\
& THEN FREE \\
3 & Unloading & wait $\mathrm{n}(2.5,0.3) \mathrm{hr}$ \\
\hline
\end{tabular}

Waktu proses muat (Loading) sebelum dilakukan perbaikan adalah selama 3 jam, dan setelah diperbaiki diubah menjadi 2 jam.

\section{Hasil Output Perbaikan Simulasi Model Pengiriman}

Selanjutnya kita jalankan simulasi model pengiriman kembali. Adapun output yang diperoleh setelah dilakukan perbaikan dalam simulasi model pengiriman yaitu: 
Tabel 7. General Result Perbaikan

\begin{tabular}{|l|l|}
\hline \multicolumn{2}{|c|}{$\begin{array}{r}\text { BCCI-RECKITT .MOD } \\
\text { (Normal Run - Rep. 1) }\end{array}$} \\
\hline & \\
Name & Value \\
\hline $\begin{array}{l}\text { Simulation } \\
\text { Time (HR) }\end{array}$ & 182 \\
\hline
\end{tabular}

Dari General result simulasi model pengiriman yang dijalankan adalah selama (8 jam simulasi harian $\times 21,75$ hari $=174$ Jam simulasi +8 jam entitas masuk awal $=$ 182 jam).

Tabel 8. Location Result Perbaikan

\begin{tabular}{|c|c|c|c|c|c|c|c|c|}
\hline \multicolumn{9}{|c|}{ BCCI-RECKITT .MOD (Normal Run - Rep. 1) } \\
\hline Name & $\begin{array}{c}\text { Sch } \\
\text { Ti } \\
\text { me } \\
(\text { H } \\
\text { R) }\end{array}$ & $\begin{array}{l}\text { C } \\
\mathbf{a} \\
\mathbf{p} \\
\mathbf{a} \\
\mathbf{c i} \\
\text { ty }\end{array}$ & $\begin{array}{c}\text { Tot } \\
\text { al } \\
\text { En } \\
\text { trie } \\
\text { s }\end{array}$ & $\begin{array}{c}\text { Av } \\
\text { g } \\
\text { Ti } \\
\text { me } \\
\text { Per } \\
\text { En } \\
\text { try } \\
\text { (M } \\
\text { IN) }\end{array}$ & $\begin{array}{c}\text { Av } \\
\text { g } \\
\text { Co } \\
\text { nte } \\
\text { nts }\end{array}$ & $\begin{array}{c}\text { Ma } \\
\text { X } \\
\text { Con } \\
\text { tent } \\
\text { s }\end{array}$ & $\begin{array}{c}\text { Cur } \\
\text { ren } \\
\text { t } \\
\text { Co } \\
\text { nte } \\
\text { nts }\end{array}$ & $\begin{array}{c}\% \\
\text { Ut } \\
\text { ili } \\
\text { za } \\
\text { tio } \\
\text { n }\end{array}$ \\
\hline $\begin{array}{c}\mathrm{PT} \\
\text { Recki } \\
\text { tt } \\
\text { Benc } \\
\text { kiser }\end{array}$ & $\begin{array}{r}182 \\
, 00\end{array}$ & $\begin{array}{l}9 \\
9 \\
9 \\
9 \\
9\end{array}$ & 173 & $\begin{array}{l}147 \\
, 37\end{array}$ & $\begin{array}{c}2,3 \\
3\end{array}$ & 5 & 4 & $\begin{array}{c}0, \\
00\end{array}$ \\
\hline
\end{tabular}

Location Result menunjukkan ada 173 rit pengiriman pada total entries PT. Reckitt Benckiser, hasil yang didapatkan lebih tinggi dari permintaan sebelumnya sebesar 172 rit pengiriman. Ini dikarenakan proses waktu yang dikurangi pada proses muat (Loading).

Tabel 9. Resource Result Perbaikan

\begin{tabular}{|c|c|c|c|c|c|c|c|c|}
\hline \multicolumn{9}{|c|}{ BCCI-RECKITT .MOD (Normal Run - Rep. 1) } \\
\hline $\begin{array}{l}\text { Na } \\
\text { me }\end{array}$ & $\begin{array}{c}\text { Uni } \\
\text { ts }\end{array}$ & $\begin{array}{c}\text { Sc } \\
\text { he } \\
\text { du } \\
\text { le } \\
\text { d } \\
\text { Ti } \\
\text { m } \\
\text { e } \\
\text { (H } \\
\text { R) }\end{array}$ & $\begin{array}{c}\text { Nu } \\
\text { mbe } \\
\text { r } \\
\text { Tim } \\
\text { es } \\
\text { Use } \\
\text { d }\end{array}$ & $\begin{array}{c}\text { Avg } \\
\text { Time } \\
\text { Per } \\
\text { Usag } \\
\text { e } \\
\text { (MI } \\
\text { N) }\end{array}$ & $\begin{array}{c}\text { Avg } \\
\text { Time } \\
\text { Trav } \\
\text { el To } \\
\text { Use } \\
\text { (MI } \\
\text { N) }\end{array}$ & $\begin{array}{c}\text { Avg } \\
\text { Time } \\
\text { Trav } \\
\text { el To } \\
\text { Park } \\
\text { (MI } \\
\text { N) }\end{array}$ & $\begin{array}{c}\% \\
\text { Blo } \\
\text { cke } \\
\text { d In } \\
\text { Tra } \\
\text { vel }\end{array}$ & $\begin{array}{c}\% \\
\text { Uti } \\
\text { liz } \\
\text { ati } \\
\text { on }\end{array}$ \\
\hline $\begin{array}{l}\mathrm{Tr} \\
\mathrm{uk} \\
\mathrm{Fu} \\
\text { so }\end{array}$ & 4 & $\begin{array}{l}7 \\
2 \\
8\end{array}$ & $\begin{array}{c}17 \\
6\end{array}$ & $\begin{array}{c}77,9 \\
7\end{array}$ & $\begin{array}{c}76,9 \\
6\end{array}$ & 0 & 0 & $\begin{array}{c}62 \\
, 4 \\
3\end{array}$ \\
\hline
\end{tabular}

Hasil Resource menampilkan penggunaan sumberdaya 4 (empat) unit truk fuso sebanyak 44 pengiriman untuk setiap truk. Tingkat penggunaan sumberdaya adalah sebesar $62,43 \%$.

\section{KESIMPULAN}

Simulasi model sistem pengiriman dapat memberikan gambaran proses pengiriman barang, apabila proses digambarkan dengan diagram alir serta data - data pengamatan yang diperoleh dapat mewakili waktu prosesnya seperti waktu proses muat (loading), waktu proses perjalanan (delivery) dan waktu proses bongkar (unloading).

Tingkat penggunaan sumberdaya (utilization) truk fuso sebelum dilakukan perbaikan yaitu sebesar 30,91\%. Setelah dilaksanakan perbaikan sistem pengiriman terdapat peningkatan sebesar $62,43 \%$.

Jumlah penggunaan armada truk Fuso dapat dikurangi, dimana sebelum diterapkan perbaikan sistem pengiriman masih menggunakan 8 (delapan) unit truk Fuso. Sesudah dilakukan perbaikan sistem pengiriman jumlah armada yang digunakan sebanyak 4 (empat) unit truk Fuso.

Efisiensi pengiriman terkait dengan cost dapat ditekan yaitu dengan perbaikan optimalisasi beban muat. Apabila biaya tiap rit pengiriman sebesar $\$ 100$ pada pengiriman bulan Januari s/d Maret 2019 dengan keseluruhan total 208 rit didapatkan biaya $\$ 100$ x $208=\$ 20800$. Setelah perbaikan beban muat dilakukan total rit keseluruhan menjadi 172 rit didapatkan biaya $\$ 100 \times 172$ rit $=\$ 17200$.

\section{DAFTAR PUSTAKA}

Arif, Muhammad. 2017. Pemodelan Sistem. Penerbit Deepublish. Yogyakarta.

Butarbutar, M. B, \& Yamin. M. (2008). Penggunaan Simulasi untuk Pemecahan Masalah Transportasi, Seminar Ilmiah Nasional Komputer dan Sistem Intelijen, ISSN,1411-6286 
Chois, Muhammad. Kurniawan, Johanes. Sihombing, Sarinah. 2018. Manajemen Logistik dan Transportasi. In Media. Bogor.

Desi Saryanti, I Gusti A. (2015). Perancangan Simulasi Optimasi Masalah Transportasi Pengiriman Barang Dengan Menggunakan Algoritma Genetika, Jurnal Sistem Dan Informatika, Vol. 10, No. 1.

Harrell. Ghosh. Bowden. 2004. Simulation Using Promodel. Mc Graw Hill Education. Singapore.

Johandinata, N. L, \& Hidayat, T. P. (2015). Usulan Perancangan dan Analisis Sistem Pengiriman Produk PT. XYZ, Jurnal Metris, 16, ISSN: 1411-3287 Periode 2 November 2015 Hal. 107 112.

Purnomo, Hari. 2003. Pengantar Teknik Industri. Penerbit Graha Ilmu. Yogyakarta.

Salim, Abbas. 2016. Manajemen Transportasi, Rajawali Pers. Depok.

Saputra, O. F, Hadi, M. P, \& Suharyadi. (2017). Simulasi Penggunaan Lahan dan Transportasi Massal untuk Pemodelan Pelayanan Jalan di Koridor Jalan Godean, Majalah Geografi Indonesia, ISSN, 0125-2790.

Wirasambada, S. (2009) Permodelan Sistem Logistik Perkotaan (City Logistics) untuk Memenuhi Pasokan Barang ke Moder Consumer Goods Retail (Studi Kasus:Kota Surabaya), Institut Teknologi Sepuluh Nopember 